\title{
FTY720 inhibits proliferation and epithelial- mesenchymal transition in cholangiocarcinoma by inactivating STAT3 signaling
}

Zhaoyang Lu ${ }^{1 \dagger}$, Jiabei Wang ${ }^{1 \dagger}$, Tongsen Zheng ${ }^{1 \dagger}$, Yingjian Liang ${ }^{1}$, Dalong Yin', Ruipeng Song ${ }^{1}$, Tiemin Pei ${ }^{1}$, Shangha Pan ${ }^{1}$, Hongchi Jiang ${ }^{1}$ and Lianxin Liu ${ }^{1,2^{*}}$

\begin{abstract}
Background: Interleukin 6 (IL-6)-mediated signal transducers and activators of transcription 3 (STAT-3) phosphorylation (activation) is aberrantly sustained in cholangiocarcinoma cells resulting in enhanced myeloid cell leukemia 1 (MCl-1) expression and resistance to apoptosis. FTY720, a new immunosuppressant, derived from ISP-1, has been studied for its putative anti-cancer properties. This study aimed to elucidate the mechanism by which FTY720 mediates antitumor effects in cholangiocarcinoma (CC) cells.

Methods: Three CC cell lines were examined, QBC939, TFK-1, and HuCCT1. The therapeutic effects of FTY720 were evaluated in vitro and in vivo. Cell proliferation, apoptosis, cell cycle, invasive potential, and epithelial- mesenchy-mal transition (EMT) were examined.

Results: FTY720 greatly inhibited CC cells proliferation and EMT in vitro and in vivo, and this effect was associated with dephosphorylation of STAT3 ${ }^{\text {tyr705 }}$. FTY720 induced apoptosis and G1 phase arrest in CC cells, and inhibited invasion of CC cells. Western blot analysis showed that FTY720 induced cleavage of caspases 3, 8 and 9, and of PARP, in a dose-dependent manner, consistent with a substantial decrease in p-STAT3, BCl-XL, BCl-2, survivin, cyclin D1, cyclin E, N-cadherin, vimentin, VEGF and TWIST1. In vivo studies showed that tumor growth and metastasis were significantly suppressed after FTY720 treatment.

Conclusions: These results suggest that FTY720 induces a significant decrease in p-STAT3, which inhibits proliferation and EMT of CC cells, and then induces G1 phase arrest and apoptosis. We have characterized a novel immunosuppressant, which shows potential anti-tumor effects on CC via p-STAT3 inhibition. FTY720 merits further investigation and warrants clinical evaluation.
\end{abstract}

Keywords: Cholangiocarcinoma, FTY720, STAT3, Apoptosis, Cell cycle

\section{Background}

Human cholangiocarcinoma (CC) arises from the epithelium of the biliary tree. CC encompasses adenocarcinomas arising in the intra or extrahepatic biliary tree and in the gall bladder. $\mathrm{CC}$ is a relatively uncommon malignancy in western countries [1], but has a high incidence

\footnotetext{
* Correspondence: liulianxin@ems.hrbmu.edu.cn

${ }^{\dagger}$ Equal contributors

'Department of Hepatic Surgery, The First Affiliated Hospital of Harbin Medical University, Key Laboratory of Hepatosplenic Surgery, Ministry of Education, No. 23 Youzheng Street, Heilongjiang Province, Harbin 150001, China

${ }^{2}$ Department of Pharmacology (the State-Province Key Laboratories of Biomedicine-Pharmaceutics of China, Key Laboratory of Cardiovascular Research, Ministry of Education), Harbin Medical University, Harbin, China
}

in Asia and Latin America [2,3]. CC is characterized by poor prognosis and a 5-year survival rate less than 5\% [4]. Currently, conventional chemotherapy and radiotherapy have not been reported to be effective in improving long-term survival [5], the only curative treatment for CC is surgical resection. However, the majority of $\mathrm{CC}$ patients shows advanced liver involvement and metastasis, and this precludes the use of curative surgical resection. Therefore, there is an urgent need to define the molecular mechanisms underlying CC proliferation and metastasis in order to develop novel therapeutic strategies.

One promising candidate for CC targeted therapy is signal transducer and activator of transcription 3 (STAT3). 
STAT3 is a transcription factor that is constitutively activated in many types of cancer, contributing to tumor progression via several mechanisms. [6-9] When phosphorylated at tyrosine ${ }^{705}$, STAT3 undergoes translocation from the cytosol to the nucleus, where it functions as a pivotal transcription factor upregulating gene transcription [10-12]. IL-6 secretion can further increase STAT3 activation levels within tumor cells via an autocrine feedback loop [6]. IL-6-activated STAT3 is crucial for survival of several types of cancer cell, including multiple myeloma, a plasmacytic B-cell malignancy $[6,13]$. Studies suggest that IL-6/STAT3 signaling is aberrant in human $\mathrm{CC}$ cells and $\mathrm{CC}$ tissues with prolonged and sustained STAT-3 phosphorylation $[14,15]$. The mechanisms responsible for this atypical IL-6 signaling response are unclear but of pathophysiological importance.

FTY720 is a synthetic sphingosine immunosuppressant, which is currently undergoing clinical trials for the prevention of kidney graft rejection [16] and the treatment of relapsing multiple sclerosis [17]. Previous studies indicate that the effect of FTY720 on prolonging the survival of allografts is attributable to the ability of its phosphorylated metabolite to inhibit T-lymphocyte infiltration by targeting several of the sphingosine-1-phosphate (S1P) receptors [18,19]. Recently, FTY720 has been reported to have a strong antitumor effect on breast cancer [20], bladder cancer [21] and leukemia [22]. So far, the feasibility of using this drug in $\mathrm{CC}$ treatment has not been studied. The precise mechanism of FTY720 action on cancer cells is not completely understood. Therefore, in this study we aimed to investigate the in vitro and in vivo anticancer potential of FTY720 and to ascertain the precise mechanism by which proliferation and metastasis are inhibited in CC cells.

We investigated the effect of FTY720 on the STAT3 cell survival pathway and found that STAT3 dephosphorylation plays a central role in cell growth arrest, apoptosis and metastasis upon administration of FTY720 to CC cell lines. Dephosphorylation of STAT3 ${ }^{\text {tyr705 }}$ results in G1 arrest and apoptosis possibly by up-regulation of $\mathrm{p} 27$, cleavage of caspase-3 and down-regulation of Mcl-1, cyclin D1 and Bcl-xL. It might also inhibit EMT by up-regulation of E-cadherin and down-regulation of Vimentin and $\mathrm{N}$-cadherin, both in vitro and in vivo.

\section{Methods}

\section{Cell lines and reagents}

The human CC cell line QBC939 was a gift from Prof. Shuguang Wang (Third Military Medical University, Chongqing, China). Human CC cell lines TFK-1 and HuCCT1 were kindly provided by the Cancer Cell Repository, Tohoku University, Japan. All cell lines were cultured in Dulbecco's modified Eagle's medium (DMEM; Gibco BRL, Grand Island, NY, USA) supplemented with 10\% fetal bovine serum (Gibco BRL), penicillin G (100,000 U/L) and streptomycin (100 mg/L; Gibco BRL) at $37^{\circ} \mathrm{C}$ in a humidified atmosphere containing $5 \% \mathrm{CO}_{2}$. FTY720 was purchased from Selleckchem (Houston, TX, USA).

\section{MTT assay}

Cell viability was assessed using the MTT assay. CC cells were seeded at $2 \times 10^{4}$ per well in 96-well flat-bottomed plates and incubated in 10\% FBS supplemented DMEM for $24 \mathrm{~h}$. Cells were treated with FTY720 at various concentrations in the same medium. Controls received dimethyl sulfoxide (DMSO) vehicle at a concentration equal to that in drug-treated cells. After 24 and $48 \mathrm{~h}$, the drugcontaining medium was replaced with $200 \mu \mathrm{L}$ of $10 \%$ FBS supplemented DMEM containing $0.5 \mathrm{mg} / \mathrm{mL} \mathrm{MTT}$, and cells were incubated in the $\mathrm{CO}_{2}$ incubator at $37^{\circ} \mathrm{C}$ for $4 \mathrm{~h}$. Medium was removed and the reduced MTT solubilized in $100 \mu \mathrm{L}$ per well of DMSO. Absorbance was then measured at $570 \mathrm{~nm}$. Six replicates were performed for each experiment.

\section{Cell cycle analysis}

Cells were treated with FTY720 and then $10^{6}$ cells were fixed in $80 \%$ ethanol at $-20^{\circ} \mathrm{C}$ for $24 \mathrm{~h}$. Fixed cells were stained according to the Cycle TESTTM PLUS DNA Reagent Kit protocol (BD Biosciences, San Jose, CA, USA) and analyzed by flow cytometry (Beckman Coulter FC 500). The experiment was repeated thrice under the same conditions.

\section{Apoptosis analysis}

FTY720 treated cells were harvested, washed twice with prechilled PBS and resuspended in $1 \times$ binding buffer at a concentration of $1 \times 10^{6}$ cells $/ \mathrm{ml}$. One hundred microliters of this cell suspension $\left(1 \times 10^{5}\right.$ cells $)$ was mixed with $5 \mu \mathrm{l}$ of Annexin V-FITC and $5 \mu \mathrm{l}$ of propidium iodide (PI) (BD Biosciences) according to the manufacturer's instructions. The mixed solution was gently vortexed and incubated in the dark at room temperature $\left(25^{\circ} \mathrm{C}\right)$ for $15 \mathrm{~min}$. Four hundred microliters of $1 \times$ dilution buffer were then added to each tube and cell apoptosis analysis was performed by flow cytometry (BD FACS Calibur) within $1 \mathrm{~h}$.

\section{Cell invasion assays}

Eight hours after FTY720 treatment, invasion was measured using 24-well BioCoat cell culture inserts (BD Biosciences, NJ, USA) with an $8 \mu \mathrm{m}$ porosity polyethylene terephthalate membrane coated with Matrigel Basement Membrane Matrix.

\section{Tumor xenografts in nude mice}

In these studies, tumor xenografts were established by standard techniques in 8-week-old nude mice (BALBc 
$\mathrm{nu} / \mathrm{nu}$ ) [23]. In brief, each mouse was injected subcutaneously with $3 \times 10^{6}$ QBC939 cells and $3 \times 10^{6}$ HuCCT1 cells suspended in PBS. Tumor size was measured by Vernier calipers, and tumor volume was calculated as described previously [24]. Once the tumors reached an average of $90 \mathrm{~mm}^{3}$, the treatment began. For the treatment group, FTY720 was administered by daily i.p. injection of $10 \mathrm{mg} / \mathrm{kg} /$ day for 20 days. After treatment, mice in both the treatment and control groups $(n=10$ in each group) were sacrificed. Tumor tissues were collected, snap-frozen and embedded in paraffin for further analysis.

\section{Ethics statement}

This study does not involve human subjects, human material, or human data. All nude mice were treated and all procedures were conducted in accordance with the guidelines for experimental animals approved by the Animal Care and Use Committee of Harbin Medical University, Harbin, China.

\section{In vivo invasive assay}

HuCCT1 cells $\left(3 \times 10^{6}\right.$ cells in $\left.200 \mu \mathrm{L}\right)$ and QBC939 $\left(3 \times 10^{6}\right.$ cells in $\left.200 \mu \mathrm{L}\right)$ were injected into the intraperitoneal cavity as previously described [25]. Animals were randomized to receive either FTY720 (10 mg/kg/d, i.p.) or vehicle at 1 week after injection. The mice were sacrificed at 4 weeks after tumor cell injection.

\section{Western blot analysis}

Protein isolation was performed as described previously [26], and western blot analysis was achieved via established protocols [27]. The primary antibodies used were against $\mathrm{N}$-cadherin, E-cadherin, p16 and vimentin (Abcam, Cambridge, MA, USA); p27, STST3, p-STAT3, cleaved PARP, cleaved caspase-3, cleaved caspase-8, cleaved caspase-9, Bcl-xL, and Bcl-2 (Cell Signaling Technology, Danvers, MA, USA); cyclin D1, VEGF, TWIST1, Bax, survivin, cyclin E, CDK2, CDK4 and $\beta$-actin (Santa Cruz Biotechnology, Santa Cruz, CA, USA).

\section{Immunofluorescence}

Briefly, cells seeded on coverslips were fixed with $4 \%$ (w/v) paraformaldehyde (Sigma-Aldrich) for $10 \mathrm{~min}$ and permeabilized with $0.1 \%(\mathrm{v} / \mathrm{v})$ Triton $\mathrm{X}-100$ for $5 \mathrm{~min}$ at room temperature. The cells were then incubated overnight with primary antibodies at $4^{\circ} \mathrm{C}$, followed by incubation with fluorescent secondary antibody for $1 \mathrm{~h}$ at room temperature. After final washes with PBS, coverslips were mounted using an anti-fade mounting solution containing 4',6-diamidino-2-phenylindole (DAPI; Vector Lab) and images were examined and captured.

\section{Immunohistochemistry}

Immunohistochemistry was performed as described previously [28] using Ki-67, CD31 and cleaved caspase-3 antibodies (Cell Signaling Technology).

\section{Statistical analysis}

All data are expressed as mean values \pm standard deviation (SD). Comparisons among multiple groups were made with a one-way analysis of variance followed by Dunnett's

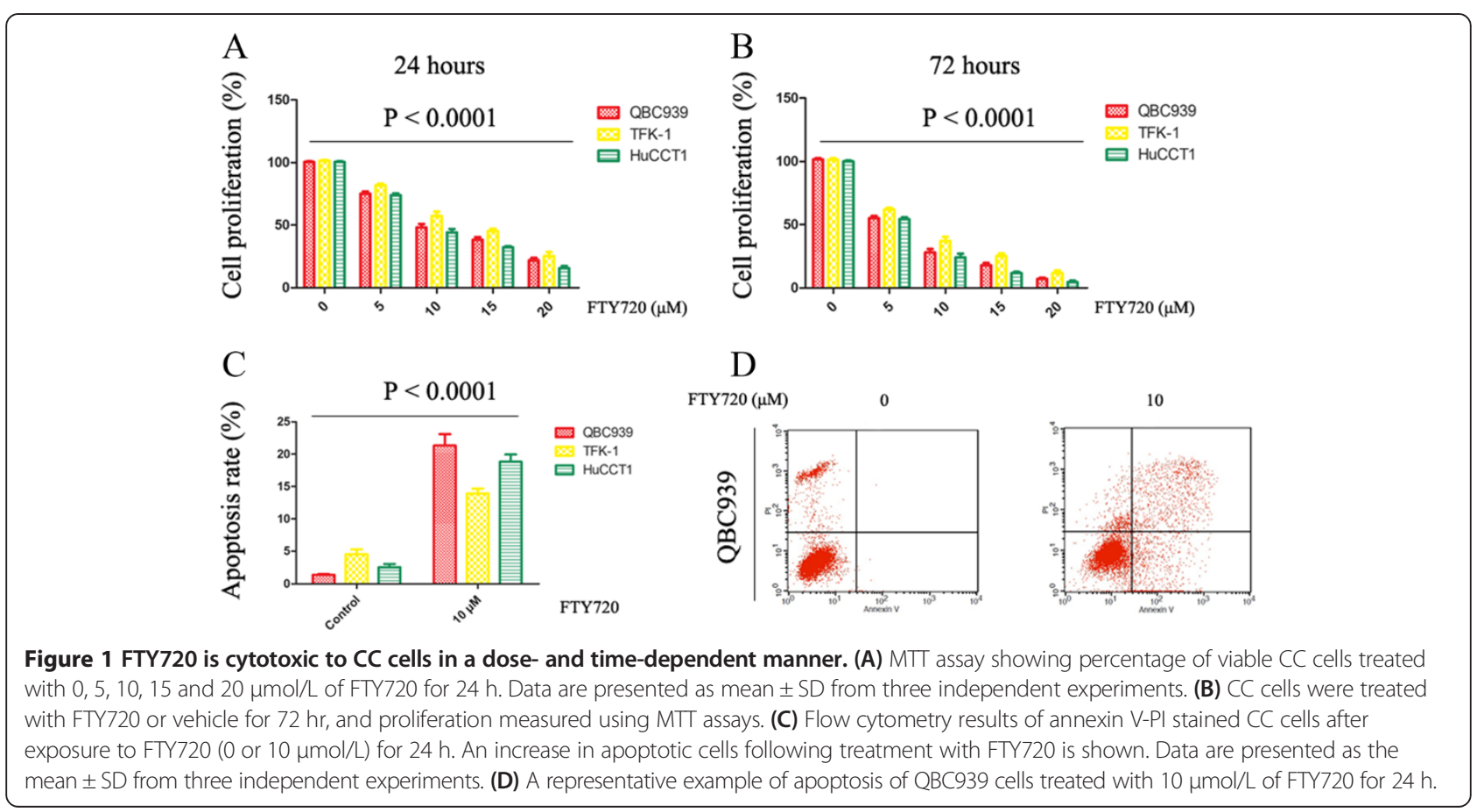


t-test. A value of " $p<0.05$ " was considered to be statistically significant.

\section{Results}

FTY720 is a potent anti-CC agent and induces apoptosis in CC cells

The in vitro activity of FTY720 against CC cells was evaluated after $24 \mathrm{~h}$ of exposure to drug. Cells were grown in the absence or presence of different concentrations $(0,5,10,15$ and $20 \mu \mathrm{mol} / \mathrm{L})$ of FTY720, and cytotoxicity was measured by the MTT assay. FTY720 effectively induced cell death in all cell lines tested (Figure 1A). The $\mathrm{IC}_{50}$ of FTY720 after $24 \mathrm{~h}$ of exposure to the drug was 9.81, 11.66 and $8.84 \mu \mathrm{mol} / \mathrm{L}$ for QBC939, TFK-1 and HuCCT1 cells, respectively. Extending drug exposure to $72 \mathrm{~h}$ resulted in additional cytotoxicity, indicating that

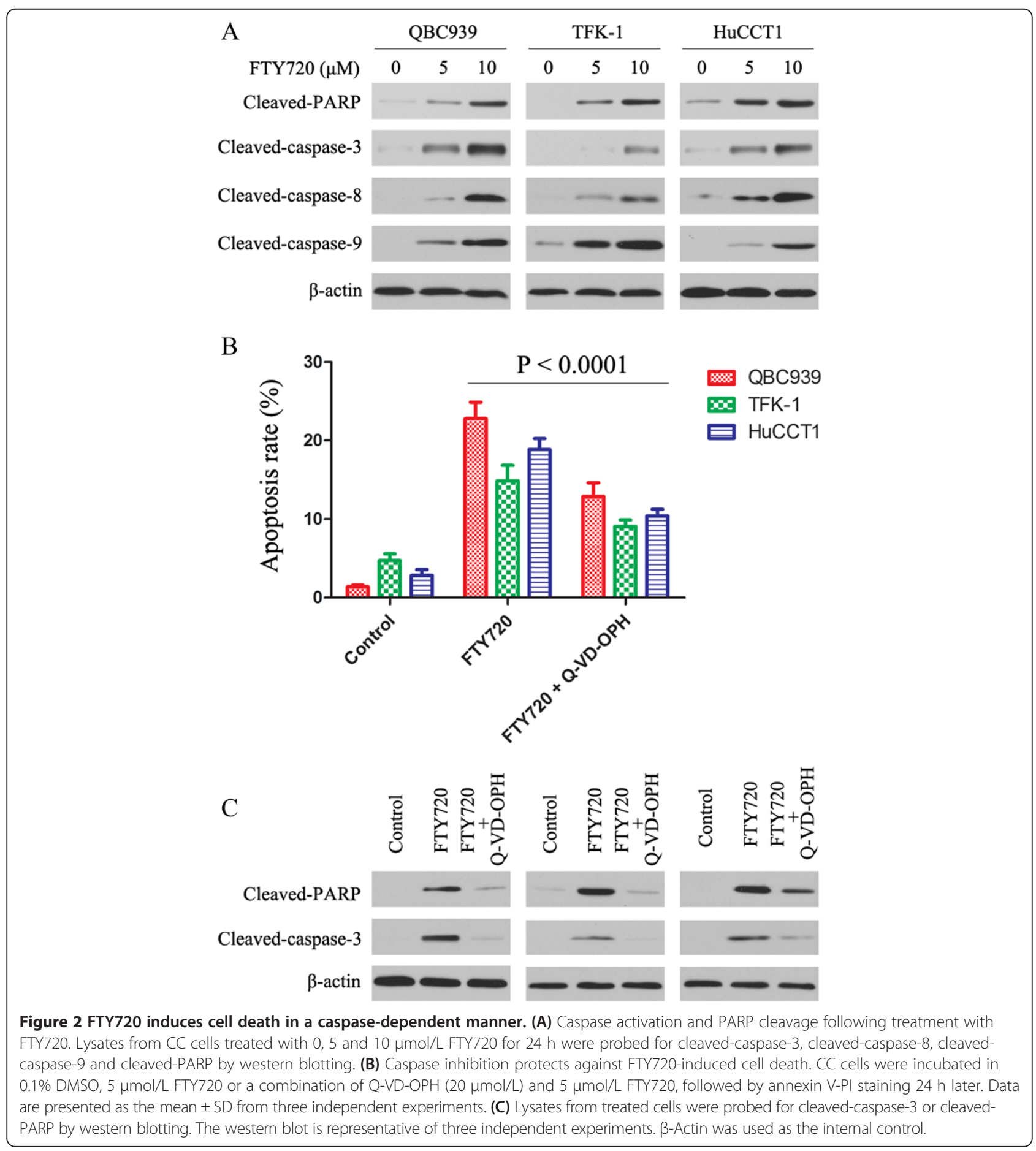


FTY720 also induced cell death in a time-dependent manner (Figure 1B).

To determine whether $\mathrm{CC}$ cell death induced by FTY720 involves apoptosis, flow cytometric analysis with annexin V-PI staining was performed. FTY720 induced obvious apoptosis in all cell lines tested at the dose of $10 \mu \mathrm{mol} / \mathrm{L}$ after $24 \mathrm{~h}$ (Figure 1C). Figure 1D is a representative example of apoptosis of QBC939 cells treated with $10 \mu \mathrm{mol} / \mathrm{L}$ FTY720 for $24 \mathrm{~h}$.

\section{FTY720 induces cell death in a caspase-dependent}

\section{manner by cleavage of caspases 3,8 and 9}

Next, we explored the effect of FTY720 on caspasedependent apoptotic pathways. FTY720 induced cleavage of caspases 3, 8 and 9, and of PARP, in a dose-dependent manner after $24 \mathrm{~h}$ incubation with the drug (Figure $2 \mathrm{~A}$ ). To determine the dependence of FTY720-induced apoptosis on the caspase pathway, we assessed the ability of the pan-caspase inhibitor, Q-VD-OPH to protect against cell death. As shown in Figure 2B, Q-VD-OPH reduced FTY720-induced cell death as determined by annexin V-PI staining and the effect was only partial. We next examined whether Q-VD-OPH actually inhibited FTY720 activation of caspase- 3 as measured by processing of the proform and downstream cleavage of PARP, which is characteristic of caspase-dependent apoptosis. CC cells were exposed to FTY720 in the presence or absence of Q-VD$\mathrm{OPH}$ and cell lysates made. As shown in Figure 2C, Q-VD-OPH greatly diminished PARP and caspase-3 cleavage as well as preventing cell death. Together, these data demonstrate that while apoptosis is induced by FTY720 mainly through caspase-dependent mechanisms, non-caspase dependent pathways may also operate.

\section{FTY720 inhibits constitutive and inducible STAT3} phosphorylation in CC cells, and affects the expression of anti- or proapoptotic proteins

We first evaluated the effect of FTY720 on the expression of p-STAT3 in CC cells. Figure 3A shows that treatment of CC cells with FTY720 for 24 h significantly reduced the level of in tyrosine-phosphorylated STAT3 although total STAT3 was unaffected. FTY720 treatment also strongly decreased the expression of $\mathrm{Bcl}-\mathrm{xL}, \mathrm{Bcl}-2$, survivin and increased the expression of Bax in CC cells. Next, we examined whether FTY720 could inhibit IL-6induced STAT3 phosphorylation in CC cells. CC cells were pretreated with FTY720 $(5 \mu \mathrm{M})$ for $24 \mathrm{~h}$ and then stimulated with IL-6 $(10 \mathrm{ng} / \mathrm{ml})$ for $15 \mathrm{~min}$. As shown in Figure 3B, IL-6 induced STAT3 phosphorylation was reduced by FTY720. These results indicate that the STAT3 pathway is likely to be an important target of FTY720 in CC cells.

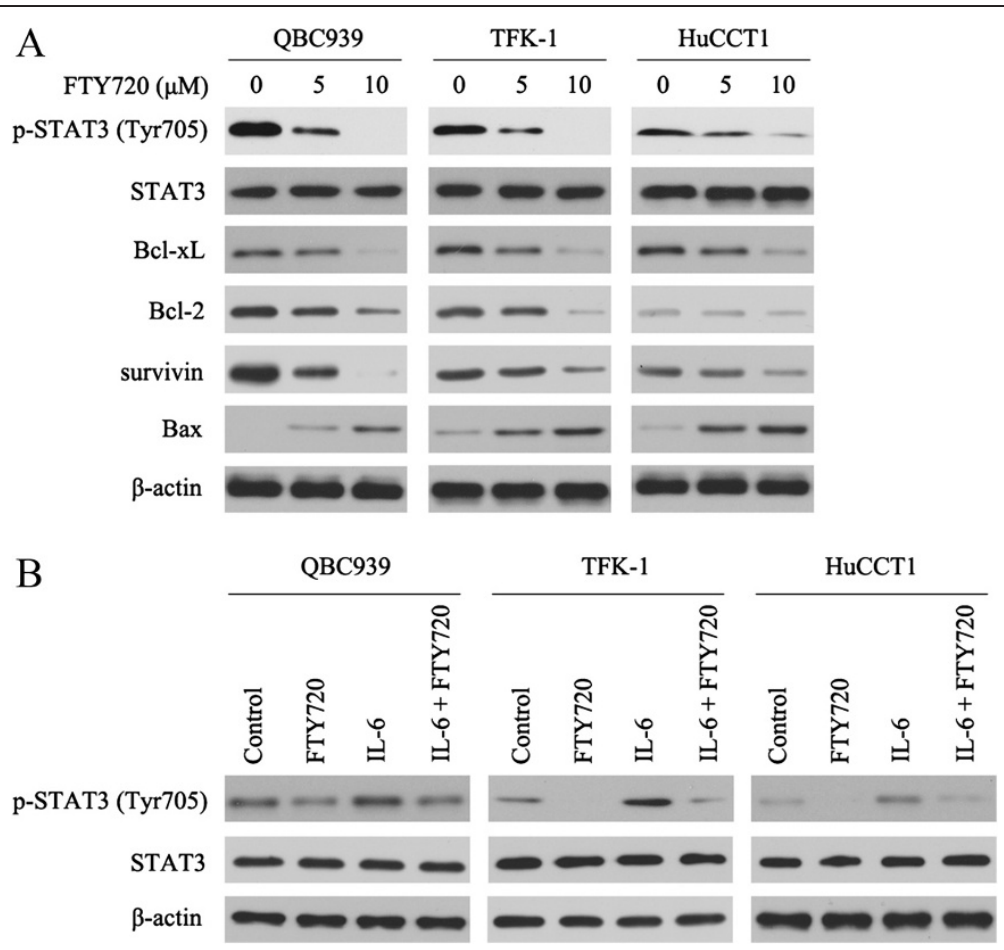

Figure 3 FTY720 reduces constitutive and inducible p-STAT3 in CC cells, and downregulates the expression of anti- or proapoptotic proteins. (A) CC cells were treated for $24 \mathrm{~h}$ with or without FTY720 and analyzed for the indicated protein by western blotting. (B) FTY720 reduced IL-6 induced p-STAT3 expression in CC cells as shown in the western blot. $\beta$-Actin was used as the internal control. All assays were performed in triplicate. 


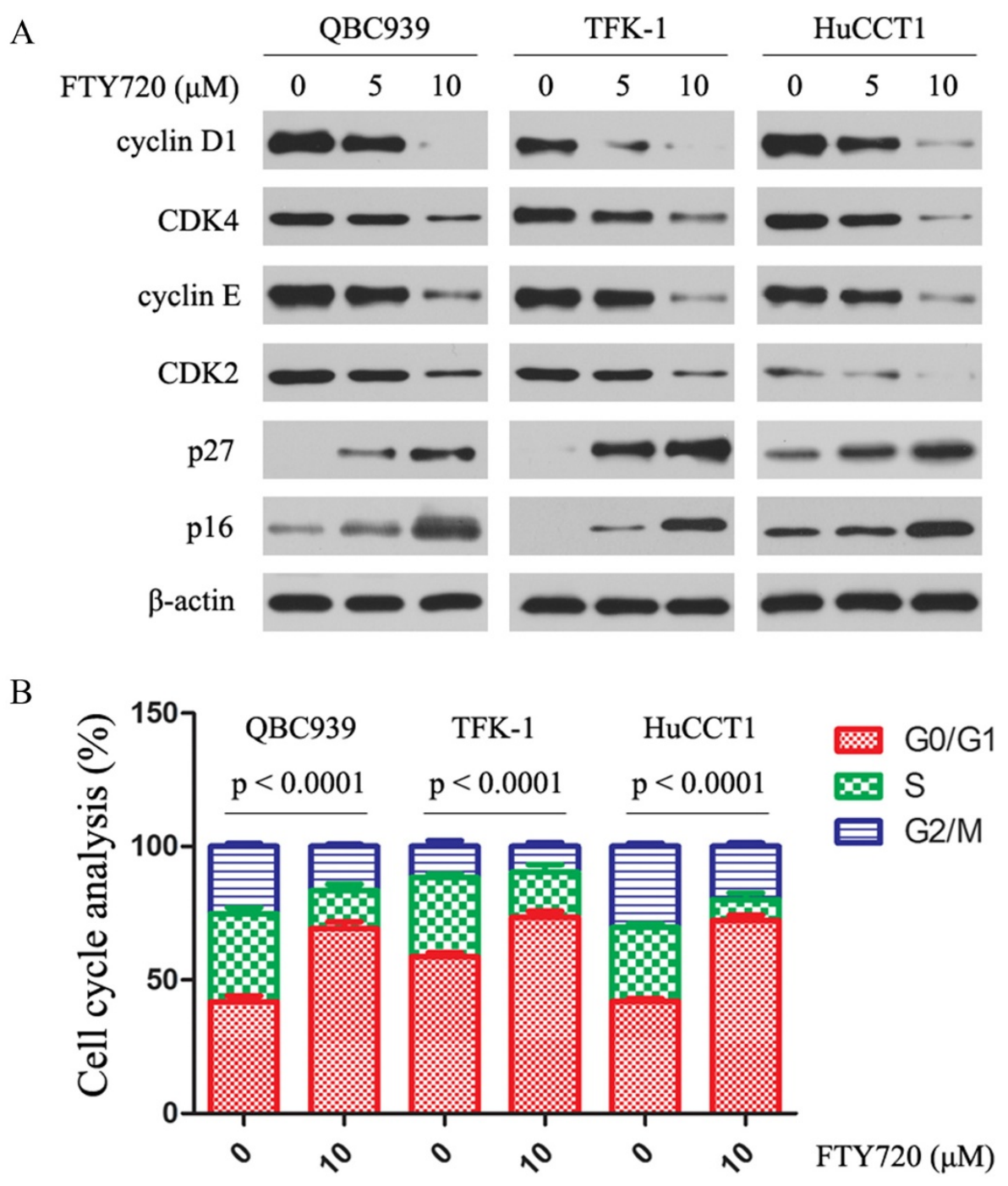

C

FTY720 $(\mu \mathrm{M})$

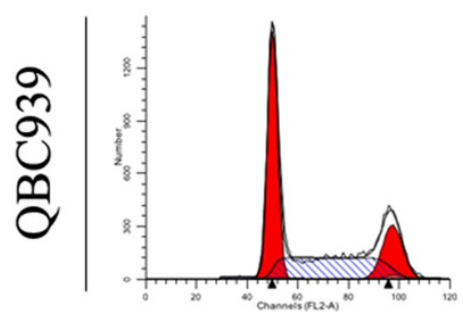

10

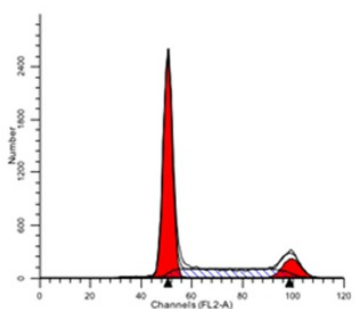

Figure 4 Effect of FTY720 on cell cycle proteins and cell cycle progression. (A) FTY720 induces expression of p16 and p27 and reduces expression of cyclin D1, CDK4, cyclin E and CDK2. CC cells were treated with FTY720 at the indicated concentrations for 24 h. Lysates were then prepared immediately and analyzed by western blotting for cyclin D1, CDK4, cyclin E, CDK2, p16 and p27. $\beta$-Actin was used as the internal control. All assays were done in triplicate. (B) Cell cycle analysis of FTY720-treated CC cells showing arrest in G1 phase. CC cells were incubated with FTY720 for $24 \mathrm{~h}$. The percentage of cells in each phase of the cell cycle is presented as the mean \pm SD from three independent experiments. Following treatment with FTY720 for 24 h, there was a significant increase in the percentage of cells in G0/G1 relative to the control group. (C) A representative example of cell cycle arrest in QBC939 cells treated with FTY720 for $24 \mathrm{~h}$. 
FTY720 downregulates cyclin D1 and cyclin E, increases p27 and p16 expression and induces $\mathrm{G} 1$ cell cycle arrest in CC cells

Next, we investigated the effect of FTY720 on cell cycle arrest of CC cells. As shown in Figure 4A, reductions in the levels of cyclin D1, CDK4, cyclin E and CDK2 were observed after FTY720 treatment for $24 \mathrm{~h}$. As increased expression of p27 results in inhibition of proliferation, we examined the effect of FTY720 on its expression and on that of p16, another cell cycle inhibitor that has been shown to be transcriptionally silenced in CC [29]. Expression of both p27 and p16 proteins was induced by FTY720 after treatment for $24 \mathrm{~h}$ (Figure 4A). Consistent with the above findings, cell cycle analysis showed that FTY720 induces G1 cell cycle arrest in CC cells (Figure 4B, C).

FTY720 inhibits the invasive potential of CC cells in vitro To determine the function of FTY720, we treated QBC939, TFK-1 and HuCCT1 cells with FTY720. FTY720 significantly inhibited their invasive capacity, as compared with DMSO-treated cells (Figure 5A). Given that FTY720 inhibits CC invasion, we investigated the effect of FTY720 on epithelial-mesenchymal transition (EMT), a critical event in tumor invasion. Western blot analysis indicated a higher expression of E-cadherin in $\mathrm{CC}$ cells treated with
FTY720. In contrast, the expression of N-cadherin, vimentin, VEGF and TWIST1 decreased in FTY720 treated CC cells (Figure 5B). As shown by immunofluorescence (Figure 5C), FTY720 markedly reduced N-cadherin and vimentin levels in CC cells, which was in good agreement with the results in Figure 5B.

\section{FTY720 inhibits tumor growth and metastasis of CC in vivo}

We further examined the effect of FTY720 on CC growth by establishing a xenograft $\mathrm{CC}$ model in nude mice. QBC939 and HuCCT1 was used for in vivo studies. Compared with the control group, FTY720 treatment resulted in a significant decrease of tumor size (Figure 6A and Additional file 1: Figure S1). The effects of FTY720 on the metastatic phenotype of CC were also examined in vivo by implanting HuCCT1 and QBC939 cells into the peritoneal cavity of nude mice. Necropsy after 4 weeks revealed that the control cells extensively colonized the visceral organs and formed multiple metastatic nodules (Figure 6B and Additional file 2: Figure S2), while the number of metastatic nodules was reduced in FTY720-treated mice. In addition, the body weight of mice from treated group was similar to the control group (Additional file 3: Figure S3A and S3B), indicating FTY720 suppress CC growth and metastasis without notable toxic side-effects. Immunohistochemistry showed

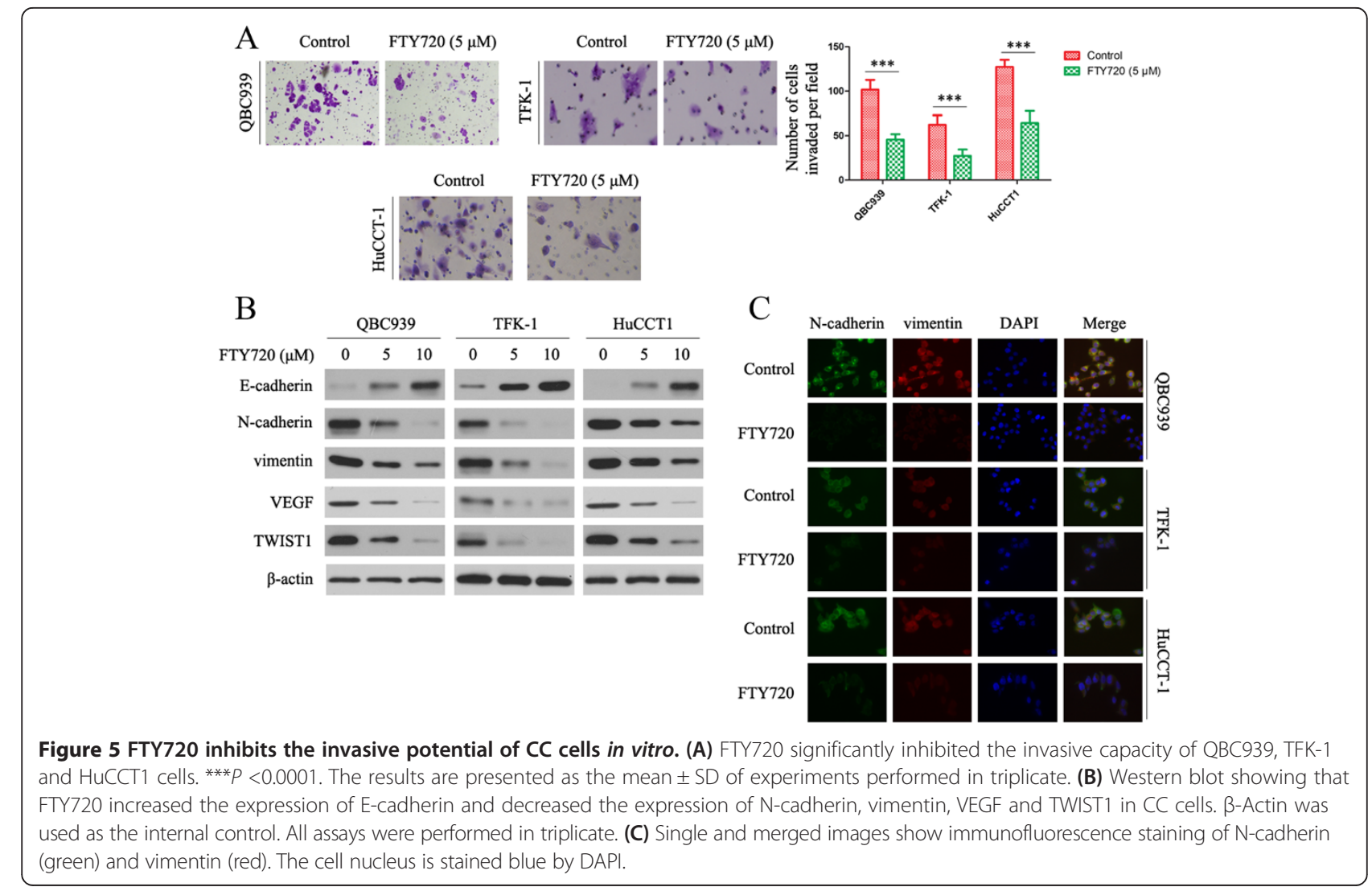




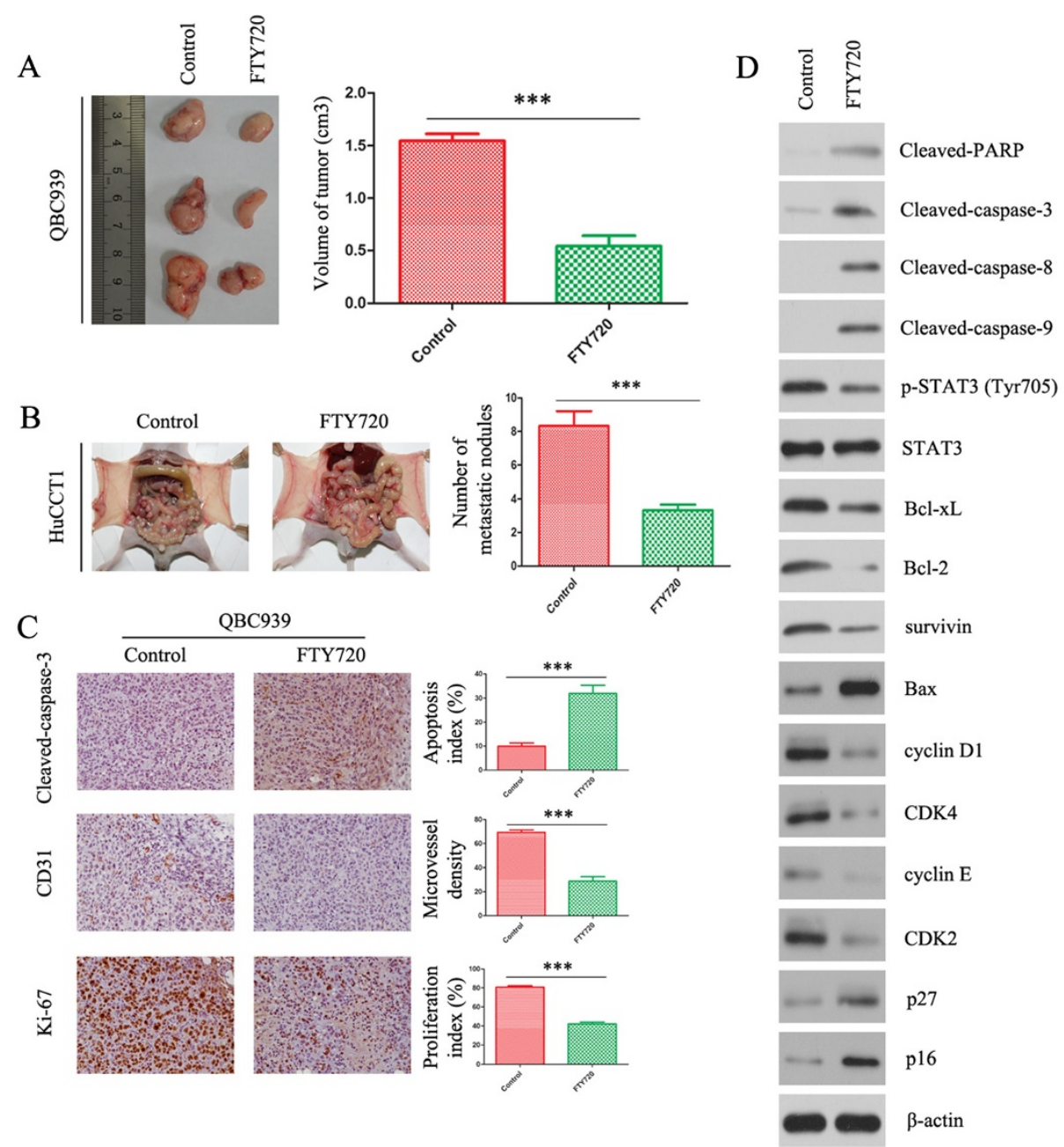

Figure 6 FTY720 inhibits proliferation and metastasis of CC in vivo. (A) Photomicrographs of xenograft tumors in nude mice. Representative images of a mouse in each group are presented. Tumor volumes in FTY720-treated mice were smaller than those of control mice. (B) The multiple tumor masses formed by the HuCCT1 cells in the FTY720-treated group were much smaller than those formed by HuCCT1 cells in the control group. (C) Tumors from different groups were immunostained for indicated molecules. CD31-stained microvessels were counted to record microvessel density. Apoptotic cells were counted to give the apoptosis index and cells expressing Ki-67 were counted to calculate the proliferation index. Pictures are representative of three independent experiments. (D) Western blot detection of the indicated molecules in tumor samples. $\beta$-Actin was used as the internal control. All assays were performed in triplicate. The results are expressed as the mean \pm SD of three independent experiments; *** $P<0.0001$.

changes of Ki-67, cleaved-caspase-3 and CD31 in the different groups (Figure 6C) respectively assess tumors' ability of proliferation, apoptosis, and forming microvessels. The relative levels of the above mentioned proteins were also analyzed in the different groups by western blotting (Figure 6D). Together, these results reveal a high propensity of FTY720 to inhibit proliferation and metastasis in CC.

\section{Discussion}

Cholangiocarcinoma is an aggressive disease, with a poor response to the treatments that are currently available, including the standard gemcitabine [30,31]. To this end, we examined a new agent for the treatment of $\mathrm{CC}$. FTY720 is a chemical substance derived by modifying an immunosuppressive metabolite and has been shown to possess anti-cancer properties in various types of cancer [32]. However, the efficacy of FTY720 against CC has not been previously assessed. Herein, we have demonstrated that FTY720 induces apoptosis and cell cycle arrest, inhibits EMT of CC cells and in vivo tumor growth in a nude mouse model without notable toxic side-effects.

The IL-6/STAT3 pathway plays an important role in human cancers. STAT proteins comprise a seven member family of latent cytoplasmic transcription factors $[10,33]$. 
Accumulating data suggest that aberrant STAT signaling, and in particular STAT3 initiated cascades, participate in the development and progression of human cancers $[10,11]$. Numerous studies have shown that STAT3 inhibitors have tumor suppressive effects on various tumors. AG490, the most popular STAT3 inhibitor, can induce CC cell apoptosis and inhibit $\mathrm{CC} /$ mycosis fungoides tumor cell proliferation $[14,15,34]$. New STAT3 inhibitors also can inhibit tumor proliferation [35,36], chemo-therapy resistance [37] and metastasis [38]. We therefore presumed that STAT3 would be a good target for CC treatment, and our results indeed show that FTY720 inhibited proliferation and EMT in CC mainly through the IL-6/STAT3 pathway.

FTY720 has been demonstrated to inhibit proliferation of various tumors $[20,39,40]$. So we tried to test whether FTY720 could inhibit CC proliferation. Cell viability analysis (MTT assays) showed that FTY720 could induce a dramatic reduction in cell viability in all three $C C$ cell lines tested. After cells were treated with FTY720 for $24 \mathrm{~h}$, we observed a significant decrease in the S-phase population, and induction of G1 arrest. FTY720 induced significant expression of the cyclin-dependent kinase (CDK) inhibitors p16 and p27. Both p16 and p27 block the formation of cyclin-CDK complexes, allowing $\mathrm{Rb}$ to become activated and to halt the cell cycle. In addition to inducing p16 and p27, FTY720 also downregulated cyclin D1 and cyclin E in CC cells contributing to arrest in the G1 phase.

FACS analysis also showed that the inhibitory effect on CC cell growth by FTY720 was also related to induction of apoptosis. Our results show that FTY720-induced apoptosis is associated with cleavage of caspases 8, 9 and 3 , and PARP, suggesting that the drug activates both the extrinsic and intrinsic apoptotic pathways. Further, FTY720-induced apoptosis is in large part dependent on caspase activation. In CC cells, FTY720 also modulates the expression of the antiapoptotic proteins. Of the Bcl-2 family members, the expression of Bcl-xL, Bcl-2 and survivin was significantly reduced, while Bax expression was increased. In additional to inhibition of tumor proliferation, numerous studies demonstrated that FTY720 could inhibit tumor metastasis $[20,41,42]$. And our study also demonstrate that incubation of CC cells with FTY720 leads to the loss of $\mathrm{N}$-cadherin and vimentin and to the accumulation of E-cadherin. Furthermore, FTY720 significantly inhibited the invasive capacity of CC cells. We also examined the ability of FTY720 to suppress the growth and metastasis of human CC cancer cell xenografts in nude mice. We found a significant reduction in relative tumor size and metastatic nodules in FTY720-treated animals compared with untreated controls. In addition, the suppression of proliferation by FTY720 was confirmed by decreased Ki-67 expression. Increased numbers of apoptotic cells and activated protein levels of apoptosis-related proteins, such as cleaved-PARP, cleaved-caspase-9, cleavedcaspase- 8 and cleaved-caspase-3, were accompanied by decreased p-STAT3 expression in the FTY720-treated animals.

IL-6 plays an important role in the growth and survival of CC cells $[43,44]$. Our results indicate that FTY720 exerts an important inhibitory effect on the IL-6 signal transduction pathway by inhibiting constitutive and inducible STAT3 phosphorylation. STAT3 directly and indirectly upregulates the expression of genes that are required for uncontrolled proliferation and invasion of tumor cells $[45,46]$. In our study, the FTY720-induced reduction of Bcl-xL, Bcl-2, N-cadherin, vimentin, cyclin $\mathrm{E}$ and cyclin D1 may result, at least in part, through an inhibitory effect on the STAT3 pathway. Importantly, FTY720 overcomes the activation of p-STST3 which was induced by IL-6.

\section{Conclusions}

In conclusion, our results show that the novel synthetic sphingosine immunosuppressant, FTY720, has potent activity against $\mathrm{CC}$ in vitro and in vivo. Its ability to target mainly the IL-6/STAT3 pathway and downstream anti-apoptotic, EMT and cell cycle proteins, suggest its viability as part of the therapeutic armamentarium for CC. Our results provide preclinical rationale for clinical development of FTY720 for the treatment of CC.

\section{Additional files}

Additional file 1: Figure S1. FTY720 inhibits proliferation of CC in vivo Photomicrographs of xenograft tumors in nude mice. Representative images of a mouse in each group are presented. Tumor volumes in FTY720-treated mice were smaller than those of control mice. ${ }^{*} P<0.05$.

Additional file 2: Figure S2. FTY720 inhibits metastasis of CC in vivo. The multiple tumor masses formed by the QBC939 cells in the FTY720treated group were much smaller than those formed by QBC939 cells in the control group. ${ }^{*} P<0.05$.

Additional file 3: Figure S3. The graph showed the body weight of the animals with tumor xenografts/without tumor xenografts in the control and treatment groups throughout the treatment period.

\section{Competing interests}

The authors declare that they have no competing interests.

\section{Authors' contributions}

ZL, JW and TZ contributed equally to this work. ZL, JW and TZ designed and carried out experiments. RS performed data collection. YL, DY and SP participated in the research. TP and HJ participated in discussions. LL supervised the project, analyzed data and wrote the paper. All authors read and approved the final manuscript.

\section{Acknowledgments}

This study was supported by Changjiang Scholars and Innovative Research Team in University (Grant No. IRT1122), the National Natural Science Foundation of China (Grant No. 81302060, No. 81301807, No. 81272705 and No. 81201878) and the Specialized Research Fund for the Doctoral Program of Higher Education (Grant No. 20102307120008). These funding agencies had no role in study design, data collection and analysis, decision to publish, or preparation of the manuscript. 
Received: 23 June 2014 Accepted: 17 October 2014

Published: 25 October 2014

\section{References}

1. Jemal A, Siegel R, Xu J, Ward E: Cancer statistics, 2010. CA Cancer J Clin 2010, 60(5):277-300

2. Shin HR, Oh JK, Masuyer E, Curado MP, Bouvard V, Fang YY, Wiangnon S, Sripa B, Hong ST: Epidemiology of cholangiocarcinoma: an update focusing on risk factors. Cancer Sci 2010, 101(3):579-585.

3. Eslick GD: Epidemiology of gallbladder cancer. Gastroenterol Clin North Am 2010, 39(2):307-330. ix

4. Khan SA, Thomas HC, Davidson BR, Taylor-Robinson SD: Cholangiocarcinoma. Lancet 2005, 366(9493):1303-1314.

5. Sirica AE: Cholangiocarcinoma: molecular targeting strategies for chemoprevention and therapy. Hepatology 2005, 41(1):5-15.

6. Yu H, Pardoll D, Jove R: STATs in cancer inflammation and immunity: a leading role for STAT3. Nat Rev Cancer 2009, 9(11):798-809.

7. Yu H, Kortylewski M, Pardoll D: Crosstalk between cancer and immune cells: role of STAT3 in the tumour microenvironment. Nat Rev Immuno 2007, 7(1):41-51.

8. Cheng F, Wang HW, Cuenca A, Huang M, Ghansah T, Brayer J, Kerr WG, Takeda K, Akira S, Schoenberger SP, Yu H, Jove R, Sotomayor EM: A critical role for Stat3 signaling in immune tolerance. Immunity 2003, 19(3):425-436

9. Kasprzycka M, Marzec M, Liu X, Zhang Q, Wasik MA: Nucleophosmin/ anaplastic lymphoma kinase (NPM/ALK) oncoprotein induces the T regulatory cell phenotype by activating STAT3. Proc Natl Acad Sci U S A 2006, 103(26):9964-9969.

10. Benekli M, Baer MR, Baumann H, Wetzler M: Signal transducer and activator of transcription proteins in leukemias. Blood 2003, 101(8):2940-2954.

11. Buettner R, Mora LB, Jove R: Activated STAT signaling in human tumors provides novel molecular targets for therapeutic intervention. Clin Cancer Res 2002, 8(4):945-954

12. Levy DE, Lee CK: What does Stat3 do? J Clin Invest 2002, 109(9):1143-1148.

13. Catlett-Falcone R, Landowski TH, Oshiro MM, Turkson J, Levitzki A, Savino R, Ciliberto G, Moscinski L, Fernández-Luna JL, Nuñez G, Dalton WS, Jove R: Constitutive activation of Stat3 signaling confers resistance to apoptosis in human U266 myeloma cells. Immunity 1999, 10(1):105-115.

14. Isomoto H, Kobayashi S, Werneburg NW, Bronk SF, Guicciardi ME, Frank DA Gores GJ: Interleukin 6 upregulates myeloid cell leukemia-1 expression through a STAT3 pathway in cholangiocarcinoma cells. Hepatology 2005 42(6):1329-1338

15. Zheng T, Hong $X$, Wang J, Pei T, Liang $Y$, Yin D, Song R, Song X, Lu Z, Qi S, Liu J, Sun B, Xie C, Pan S, Li Y, Luo X, Li S, Fang X, Bhatta N, Jiang H, Liu L: Gankyrin promotes tumor growth and metastasis through activation of IL-6/STAT3 signaling in human cholangiocarcinoma. Hepatology 2014, 59(3):935-946

16. Tedesco-Silva H, Mourad G, Kahan BD, Boira JG, Weimar W, Mulgaonkar S, Nashan B, Madsen S, Charpentier B, Pellet P, Vanrenterghem Y: FTY720, a novel immunomodulator: efficacy and safety results from the first phase 2A study in de novo renal transplantation. Transplantation 2004, 77(12):1826-1833.

17. Kappos L, Antel J, Comi G, Montalban X, O'Connor P, Polman CH, Haas T, Korn AA, Karlsson G, Radue EW: Oral fingolimod (FTY720) for relapsing multiple sclerosis. N Engl J Med 2006, 355(11):1124-1140.

18. Brinkmann V, Davis MD, Heise CE, Albert R, Cottens S, Hof R, Bruns C Prieschl E, Baumruker T, Hiestand P, Foster CA, Zollinger M, Lynch KR: The immune modulator FTY720 targets sphingosine 1-phosphate receptors. J Biol Chem 2002, 277(24):21453-21457.

19. Graler MH, Goetzl EJ: The immunosuppressant FTY720 down-regulates sphingosine 1-phosphate G-protein-coupled receptors. FASEB J 2004, 18(3):551-553

20. Azuma H, Takahara S, Ichimaru N, Wang JD, Itoh Y, Otsuki Y, Morimoto J, Fukui R, Hoshiga M, Ishihara T, Nonomura N, Suzuki S, Okuyama A, Katsuoka $Y$ : Marked prevention of tumor growth and metastasis by a novel immunosuppressive agent, FTY720, in mouse breast cancer models. Cancer Res 2002, 62(5):1410-1419.

21. Azuma H, Takahara S, Horie S, Muto S, Otsuki Y, Katsuoka Y: Induction of apoptosis in human bladder cancer cells in vitro and in vivo caused by FTY720 treatment. J Urol 2003, 169(6):2372-2377.
22. Matsuoka $Y$, Nagahara $Y$, Ikekita M, Shinomiya T: A novel immunosuppressive agent FTY720 induced Akt dephosphorylation in leukemia cells. Br J Pharmacol 2003, 138(7):1303-1312.

23. Whitnall M, Howard J, Ponka P, Richardson DR: A class of iron chelators with a wide spectrum of potent antitumor activity that overcomes resistance to chemotherapeutics. Proc Natl Acad Sci U S A 2006, 103(40):14901-14906.

24. Balsari A, Tortoreto M, Besusso D, Petrangolini G, Sfondrini L, Maggi R, Menard S, Pratesi G: Combination of a CpG-oligodeoxynucleotide and a topoisomerase I inhibitor in the therapy of human tumour xenografts. Eur J Cancer 2004, 40(8):1275-1281.

25. Itoh K, Yoshioka K, Akedo H, Uehata M, Ishizaki T, Narumiya S: An essential part for Rho-associated kinase in the transcellular invasion of tumor cells. Nat Med 1999, 5(2):221-225.

26. Dunn LL, Sekyere EO, Suryo Rahmanto $Y$, Richardson DR: The function of melanotransferrin: a role in melanoma cell proliferation and tumorigenesis. Carcinogenesis 2006, 27(11):2157-2169.

27. Gao J, Richardson DR: The potential of iron chelators of the pyridoxal isonicotinoyl hydrazone class as effective antiproliferative agents, IV: the mechanisms involved in inhibiting cell-cycle progression. Blood 2001, 98(3):842-850.

28. Chua CW, Lee DT, Ling MT, Zhou C, Man K, Ho J, Chan FL, Wang X, Wong YC: FTY720, a fungus metabolite, inhibits in vivo growth of androgenindependent prostate cancer. Int J Cancer 2005, 117(6):1039-1048.

29. Tannapfel A, Benicke M, Katalinic A, Uhlmann D, Kockerling F, Hauss J, Wittekind C: Frequency of p16(INK4A) alterations and K-ras mutations in intrahepatic cholangiocarcinoma of the liver. Gut 2000, 47(5):721-727.

30. Thongprasert $S$ : The role of chemotherapy in cholangiocarcinoma. Ann Oncol 2005, 16(Suppl 2):ii93-ii96.

31. Briggs CD, Neal CP, Mann CD, Steward WP, Manson MM, Berry DP: Prognostic molecular markers in cholangiocarcinoma: a systematic review. Eur J Cancer 2009, 45(1):33-47.

32. Liu Q, Zhao X, Frissora F, Ma Y, Santhanam R, Jarjoura D, Lehman A, Perrotti D Chen CS, Dalton JT, Muthusamy N, Byrd JC: FTY720 demonstrates promising preclinical activity for chronic lymphocytic leukemia and lymphoblastic leukemia/lymphoma. Blood 2008, 111(1):275-284

33. Heinrich PC, Behrmann I, Haan S, Hermanns HM, Muller-Newen G, Schaper F: Principles of interleukin (IL)-6-type cytokine signalling and its regulation. Biochem J 2003, 374(Pt 1):1-20.

34. Nielsen M, Kaltoft $K$, Nordahl M, Ropke C, Geisler C, Mustelin T, Dobson P, Svejgaard A, Odum N: Constitutive activation of a slowly migrating isoform of Stat3 in mycosis fungoides: tyrphostin AG490 inhibits Stat3 activation and growth of mycosis fungoides tumor cell lines. Proc Natl Acad Sci U S A 1997, 94(13):6764-6769.

35. Rath KS, Naidu SK, Lata P, Bid HK, Rivera BK, McCann GA, Tierney BJ, Elnaggar AC, Bravo V, Leone G, Houghton P, Hideg K, Kuppusamy P, Cohn DE, Selvendiran K: HO-3867, a safe STAT3 inhibitor, is selectively cytotoxic to ovarian cancer. Cancer Res 2014, 74(8):2316-2327.

36. Chen $\mathrm{H}$, Yang Z, Ding C, Xiong A, Wild C, Wang L, Ye N, Cai G, Flores RM, Ding Y, Shen Q, Zhou J: Discovery of potent anticancer agent HJC0416, an orally bioavailable small molecule inhibitor of signal transducer and activator of transcription 3 (STAT3). Eur J Med Chem 2014, 82:195-203.

37. Eiring AM, Page BD, Kraft IL, Mason CC, Vellore NA, Resetca D, Zabriskie MS, Zhang TY, Khorashad JS, Engar AJ, Reynolds KR, Anderson DJ, Senina A, Pomicter AD, Arpin CC, Ahmad S, Heaton WL, Tantravahi SK, Todic A, Colaguori R, Moriggl R, Wilson DJ, Baron R, O'Hare T, Gunning PT, Deininger MW: Combined STAT3 and BCR-ABL1 inhibition induces synthetic lethality in therapy-resistant chronic myeloid leukemia. Leukemia 2014 [Epub ahead of print].

38. Gu L, Talati P, Vogiatzi P, Romero-Weaver AL, Abdulghani J, Liao Z, Leiby B, Hoang DT, Mirtti T, Alanen K, Zinda M, Huszar D, Nevalainen MT: Pharmacologic suppression of JAK1/2 by JAK1/2 inhibitor AZD1480 potently inhibits IL-6-induced experimental prostate cancer metastases formation. Mol Cancer Ther 2014, 13(5):1246-1258.

39. Hung JH, Lu YS, Wang YC, Ma YH, Wang DS, Kulp SK, Muthusamy N, Byrd JC, Cheng AL, Chen CS: FTY720 induces apoptosis in hepatocellular carcinoma cells through activation of protein kinase $C$ delta signaling. Cancer Res 2008, 68(4):1204-1212.

40. Liao A, Broeg K, Fox T, Tan SF, Watters R, Shah MV, Zhang LQ, Li Y, Ryland L, Yang J, Aliaga C, Dewey A, Rogers A, Loughran K, Hirsch L, Jarbadan NR, Baab KT, Liao J, Wang HG, Kester M, Desai D, Amin S, Loughran TP Jr, Liu X: 
Therapeutic efficacy of FTY720 in a rat model of NK-cell leukemia. Blood 2011, 118(10):2793-2800.

41. Li CX, Shao Y, Ng KT, Liu XB, Ling CC, Ma YY, Geng W, Fan ST, Lo CM, Man K: FTY720 suppresses liver tumor metastasis by reducing the population of circulating endothelial progenitor cells. PLoS One 2012, 7(2):e32380.

42. Chua CW, Chiu YT, Yuen HF, Chan KW, Man K, Wang X, Ling MT, Wong YC: Suppression of androgen-independent prostate cancer cell aggressiveness by FTY720: validating Runx2 as a potential antimetastatic drug screening platform. Clin Cancer Res 2009, 15(13):4322-4335.

43. Okada K, Shimizu Y, Nambu S, Higuchi K, Watanabe A: Interleukin-6 functions as an autocrine growth factor in a cholangiocarcinoma cell line. J Gastroenterol Hepatol 1994, 9(5):462-467.

44. Park J, Tadlock L, Gores GJ, Patel T: Inhibition of interleukin 6-mediated mitogen-activated protein kinase activation attenuates growth of a cholangiocarcinoma cell line. Hepatology 1999, 30(5):1128-1133.

45. Yu H, Jove R: The STATs of cancer-new molecular targets come of age. Nat Rev Cancer 2004, 4(2):97-105.

46. Balanis N, Wendt MK, Schiemann BJ, Wang Z, Schiemann WP, Carlin CR: Epithelial to mesenchymal transition promotes breast cancer progression via a fibronectin-dependent STAT3 signaling pathway. J Biol Chem 2013, 288(25):17954-17967.

doi:10.1186/1471-2407-14-783

Cite this article as: Lu et al.: FTY720 inhibits proliferation and epithelialmesenchymal transition in cholangiocarcinoma by inactivating STAT3 signaling. BMC Cancer 2014 14:783.

\section{Submit your next manuscript to BioMed Central and take full advantage of:}

- Convenient online submission

- Thorough peer review

- No space constraints or color figure charges

- Immediate publication on acceptance

- Inclusion in PubMed, CAS, Scopus and Google Scholar

- Research which is freely available for redistribution 